Revue d'histoire de l'Amérique française

REVUE D'HISTOIRE DE L'AMÉRIQUE FRANÇAISE

BUIES, Arthur, Chroniques. Tome 1. Édition critique par

Francis PARMENTIER. Montréal, Presses de l'Université de

Montréal, coll. « Bibliothèque du Nouveau Monde », 1986. 675 p. $60,00 \$$.

\title{
Pierre Trépanier
}

Volume 40, numéro 4, printemps 1987

URI : https://id.erudit.org/iderudit/304501ar

DOI : https://doi.org/10.7202/304501ar

Aller au sommaire du numéro

Éditeur(s)

Institut d'histoire de l'Amérique française

ISSN

0035-2357 (imprimé)

1492-1383 (numérique)

Découvrir la revue

Citer ce compte rendu

Trépanier, P. (1987). Compte rendu de [BUIES, Arthur, Chroniques. Tome 1. Édition critique par Francis PARMENTIER. Montréal, Presses de l'Université de Montréal, coll. « Bibliothèque du Nouveau Monde », 1986. 675 p. 60,00 \$.] Revue d'histoire de l'Amérique française, 40(4), 598-600.

https://doi.org/10.7202/304501ar d'utilisation que vous pouvez consulter en ligne.

https://apropos.erudit.org/fr/usagers/politique-dutilisation/ 
BUIES, Arthur, Chroniques. Tome 1. Édition critique par Francis PARMENTIER. Montréal, Presses de l'Université de Montréal, coll. «Bibliothèque du Nouveau Monde», 1986. 675 p. 60,00\$

L'éditeur de Buies nous convie ici au plaisir de lire Les Chroniques canadiennes, humeurs et caprices, 1884 (première édition, 1873). Il réserve pour le tome 2 Les Chroniques, Voyages, etc., etc. (1873) et Les Petites Chroniques pour 1877 (1878). Le lecteur ne peut que souhaiter qu'il puisse réaliser son projet de publier un jour la correspondance de cet auteur québécois, qui avait l'étoffe d'un grand écrivain, mais qui a dilapidé ses dons, faute de discipline. La chronique est un genre littéraire qui résiste mal à l'usure du temps et il faut reconnaître que bien des pages de Buies ne présentent quelque intérêt que parce que le style et un esprit pétillant les relèvent. D'autres passages, en revanche, nous introduisent dans l'intimité d'une société et d'une époque révolues: celles-là n'ont pas de prix pour l'historien et l'érudit.

L'édition critique est une discipline exigeante, régie par des règles sévères. Peut-être conviendrait-il d'en assouplir quelques-unes? Ainsi est-il indispensable de relever toutes les variantes, même les plus insignifiantes? On peut avoir ses doutes là-dessus. Mais personne ne remettra en question la bonne 
volonté et la patience de l'éditeur de Buies, dont le travail est généralement satisfaisant, sans être parfait. L'introduction, par exemple, fera sourciller plus d'un historien de métier. L'éditeur connaît-il assez le siècle dont il parle? A-til assimilé et intégré ses lectures? Manifeste-t-il assez de sens critique par rapport à son héros et à la représentation caricaturale que ce dernier donne de son temps? Il ne suffit pas de relever la tendance à l'hyperbole, dans l'éloge autant que dans le dénigrement d'ailleurs (voir le parallèle Papineau-Cartier), encore faut-il ne pas en être dupe. Et comment expliquer certains propos carrément fantaisistes, autrement que par un excès de littérature? «Les écrits [de Buies] en faveur de la colonisation, lit-on, affaiblissent le monopole clérical dans le domaine scolaire, notamment par la distribution de ce type d'ouvrage dans les écoles» (p. 27). Ailleurs l'éditeur manque de discernement dans ses enthousiasmes. A propos de notations particulièrement faibles où Buies se révèle piètre observateur et d'une incuriosité désarmante, il admire les «comparaisons qui ne manquent pas d'intérêt entre la «vieille» structure sociale du Québec et l'égalitarisme démocratique des populations de la Baie-des-Chaleurs» (p. 8). L'égalitarisme démocratique au royaume des Robin, des Le Boutillier, des Fruing, des Fraser et des Ferguson! Buies traverse le Nord du Nouveau-Brunswick. Tout ne lui paraît que prospérité et harmonie (sauf à contredire en détail, quelques lignes plus bas, ce jugement d'ensemble). Sur les Acadiens, il n'a strictement rien à dire (l'éditeur n'a pas entendu ce silence tonitruant). Buies devait être dans une de ses périodes salonnardes. Il y a du snob chez Buies, par intermittence. A moins que le hot scotch, lui brouillant la vue et lui coupant les jambes, lui ait rendu pour lors toute exploration impossible. Bref, pour en finir avec l'introduction, on peut regretter que l'éditeur, qui est un littéraire, n'ait pas d'abord fait porter son étude sur le texte même, par exemple pour éclairer les variantes dans leur portée idéologique ou leur valeur stylistique, ce à quoi sa formation le préparait davantage.

Quant au choix des notes, il n'est pas toujours heureux. On ne doit retenir que celles qui aident à comprendre le texte. Ce n'est le lieu ni de l'érudition gratuite, ni de la prolixité, et il convient de reconnaître au lecteur un minimum d'intelligence. Buies parle du quac qui «lâchait [...] le cri sec et dur qui lui a valu son nom». Identifiant en note cet oiseau, l'éditeur croit devoir ajouter: «Ses cris «couac, couac» lui ont valu son surnom» (p. 329). Ailleurs Buies soutient que l'on naît «conservateur dans les concessions du Canada». L'éditeur juge à bon droit que le mot concession appelle une note, mais au lieu d'expliquer que ce terme désigne les territoires ouverts récemment à la colonisation ou encore les rangs les plus éloignés du village (cf. le Bélisle), il énumère les conditions auxquelles l'Etat québécois concédait les terres aux colons (p. 191). Parfois les renseignements sont erronés: «Les catholiques du Nouveau-Brunswick [...] contrairement aux protestants, s'étaient prononcés en faveur de la Confédération» (p. 198). Buies a-t-il la fantaisie de mentionner les Chinois et les Cris de la Colombie britannique? L'éditeur ne résiste pas au plaisir de faire une autre note: «La Colombie britannique comptait en 1871, 16000 blancs, 1000 Chinois et 45000 métis» (p. 91). On admettra que cela fait beaucoup de Métis et fort peu d'Amérindiens.

Pour ce qui est de la normalisation, elle semble judicieuse; l'établissement du texte a été bien fait. Les coquilles malheureusement sont assez nombreuses, de même que les erreurs de ponctuation. 
La bibliographie, excellente, est présentée de façon raisonnée. La table des matières est étique. Curieusement, l'éditeur nous console en reproduisant les tables des matières de 1873 et de 1884 , ce qui soulève toutefois le problème de la pagination (celle de 1884 est intégrée au texte, ce qui rend la consultation difficile; on doit se passer de celle de 1873). Les index brillent par leur absence: il faut s'armer de patience et feuilleter. On échangerait volontiers la moitié des variantes et le quart de l'introduction contre un bon index.

On jurerait que les professeurs de lettres ont le style de plus en plus gâté par le pédantisme scolaire, ce qui invite à des rapprochements piquants. D'une lutte d'idées, qui n'est pas sans grandeur, l'éditeur écrit: «Depuis 1858, il est vrai, le torchon brûle entre Mgr Bourget, évêque de Montréal, et l'Institut canadien» (p. 13), - alors que de pauvres polémiques de journaliste partisan deviennent sous sa plume «une relation dialectique avec la presse conservatrice et cléricale» (p. 19). A force de grandiloquence, l'éditeur finit par se faire illusion à lui-même. Buies, trop marqué politiquement, est congédié par le conservateur Boucherville, élu en partie pour assainir les finances après les extravagances de Mercier. La version de l'éditeur est moins prosaïque: «Ainsi, en voulant institutionnaliser la littérature «nationale» et en faire une activité «utile», Buies se mettait à la merci des caprices de la politique» (p. 34). Buies n'avait-il pas assumé, en 1869, «le rôle du prophète révolutionnaire, dans la double tradition philosophique et romantique inspirée de Voltaire et de Hugo» (p. 20)? Il était donc dans l'ordre qu'il fût victime de son destin, — victime, mais pas tout à fait martyr puisqu'il a profité des achats de livres du secrétariat provincial, «quel que fût le titulaire et quelle que fût son allégeance politique» (p. 488 , note 3 ).

Buies méritait une édition critique. Il fut, dans la vie intellectuelle du Québec, l'un des représentants les plus doués du libéralisme d'inspiration française. Sa pensée manquait sans doute de précision et de fermeté («je ne demande pas à des nouveaux lutteurs quel est leur programme» [p. 544]), mais elle rend fort bien la sensibilité d'une famille spirituelle, ses aspirations, ses agacements. De son peuple, il fut un censeur sévère jusqu'à l'outrance («nous croupissons dans une fange sans fond» [p. 560]) et parfois apparemment inconséquent: annexioniste, ne reprochait-il pas aux Canadiens français d'émigrer en masse aux Etats-Unis? Le nationalisme de Buies exigerait d'ailleurs une étude approfondie; il était loin d'avoir l'assurance qu'il affichait à l'occasion. Tapi dans quelque repli de sa conscience, le scepticisme guettait le moindre signe d'abattement pour fondre sur sa proie («les fétiches de l'enfance, les objets d'un culte passionné, les idoles d'une prédilection enthousiaste, tout cela a disparu sous le souffle de la critique et de l'analyse historiques» [p. 567]). Cette fragilité même est précieuse en ce qu'elle dévoile des ambivalences et des interrogations là où l'histoire a trouvé commode d'affronter des positions intellectuelles aux contours parfaitement définis et purs de tout recoupement. Le tome second des Chroniques sera le bienvenu. 